\title{
What are the determinants of quality of life in people with cervical dystonia?
}

\section{Y Ben-Shlomo, L Camfield, T Warner, on behalf of the ESDE collaborative group}

See end of article for authors' affiliations

Correspondence to

Dr Yoav Ben-Shlomo

Department of Social

Medicine, Canynge Hall,

Whiteladies Road,

University of Bristol, Bristol

BS8 2PR, UK;

y.ben-shlomo@bristol.ac.uk

Received

7 July 2001

In revised form

29 November 2001

Accepted

5 December 2001
Background: Little is known about the quality of life in patients with cervical dystonia, although pain and depression are relatively common.

Objective: To test the hypothesis that an individual's ability to cope with the disease will modify the association of intrinsic, extrinsic, and disease related factors with quality of life.

Methods: Patients with cervical dystonia diagnosed by a movement disorder specialist were recruited from seven European countries. Data on quality of life (SF-36), measures of coping, and intrinsic, extrinsic, and disease related factors were collected by a self completed postal questionnaire.

Results: 289 patients (101 men and 188 women), mean age 55 years, completed the questionnaire. Both physical and mental quality of life scores were predicted by self esteem and self deprecation, educational level, employment status, social support, response to botulinum toxin, disease severity, social participation, stigma, acceptance of illness, anxiety, and depression. In multivariable analyses, the strongest predictors were anxiety and depression. Severe depression was associated with a 19.1 point decrement in the physical summary score $(95 \%$ confidence interval, -31.7 to $-6.6 ; p=0.003)$; however, disease duration and severity remained predictors.

Conclusions: Care for patients with cervical dystonia must not only focus on reducing the severity of the dystonia but also on the psychological wellbeing of the patient. Interventions aimed at treating depression or anxiety, especially of a cognitive nature, may have a large impact on improving quality of life.
$\mathrm{P}$ rimary cervical dystonia is the commonest form of focal dystonia. It is defined as twisting or turning of the neck, or displacement of the head, caused by involuntary muscle contractions. Onset of cervical dystonia is in adult life, usually between the fourth and sixth decades, and women are affected 1.5 to 1.9 times more often than men. ${ }^{1}$ Symptoms develop slowly, with pulling or tugging in the neck or twisting or jerking of the head. Head tremor is also common.

Epidemiological data on the prevalence of cervical dystonia are sparse. Studies from Europe and the USA have found prevalences of between 57 and 90 per million, although in Finland the figure was much higher, at 233 per million. ${ }^{2}{ }^{3}$ There is little published information on the impact of cervical dystonia on the quality of life and what factors may modify a patient's ability to cope with this disease. ${ }^{45}$ Unlike other forms of focal dystonia, pain is a predominant feature and is reported in up to $75 \%$ of patients, ${ }^{6}$ while depression has been documented in $24 \%$ of patients. ${ }^{5}$

We have reported previously that cervical dystonia had a significant impact on the quality of life as assessed by the short form 36 (SF-36) generic quality of life measure, ${ }^{7}$ and the impact was comparable to that of more serious neurological conditions (multiple sclerosis, Parkinson's disease, stroke). Although patients with cervical dystonia had the best physical function score, they scored worst for mental health and emotional role limitation. They also rated their energy and vitality, physical role limitation, and social function significantly worse than either Parkinson's disease patients or long term survivors of stroke. The reasons for this large negative effect were not clear. In addition, some patients were able to cope well with the disease, with relatively little deterioration in their quality of life.

In this study we examined whether differences in reported quality of life among cervical dystonia patients can be explained by intrinsic (for example, premorbid and demographic), extrinsic (social environment), and disease related variables ( severity, duration). We hypothesised that the way in which individuals respond to their disease is a key intermediary between explanatory variables and the quality of life.

\section{METHODS}

Patients with primary or idiopathic cervical dystonia were identified by the ESDE Collaborative Group. ${ }^{12}$ All patients were diagnosed by a movement disorder specialist from seven European countries (listed at the end of the article). Patients with secondary dystonia were excluded.

Patients received a postal questionnaire containing a range of questions, including the SF-36 and various other measures of psychological health, social participation, and support (see below). The questionnaire was translated and back translated for every language to ensure accuracy and comparability. Completed questionnaires were returned and data collated on a central database for analysis.

\section{Outcome measure}

Our outcome measure for quality of life was the SF- $36,{ }^{8}$ a validated health status measure with eight areas-four physical and four emotional-that cover activities of daily living, emotional state, pain, fatigue, social participation, and perceptions of health. A higher score indicates a better quality of life. The items can be summed to give scores out of 100. In addition, the various areas can be aggregated to generate a physical and mental summary score out of 100 .

\section{Explanatory and intermediary variables}

On the basis of past knowledge and experience, we proposed that quality of life would be determined by a variety of different domains (fig 1).

Intrinsic factors were variables that were either demographic (age, sex) or reflected premorbid personality characteristics (self esteem, self deprecation). Self esteem and a tendency to self deprecate were measured by the Rosenberg self esteem 


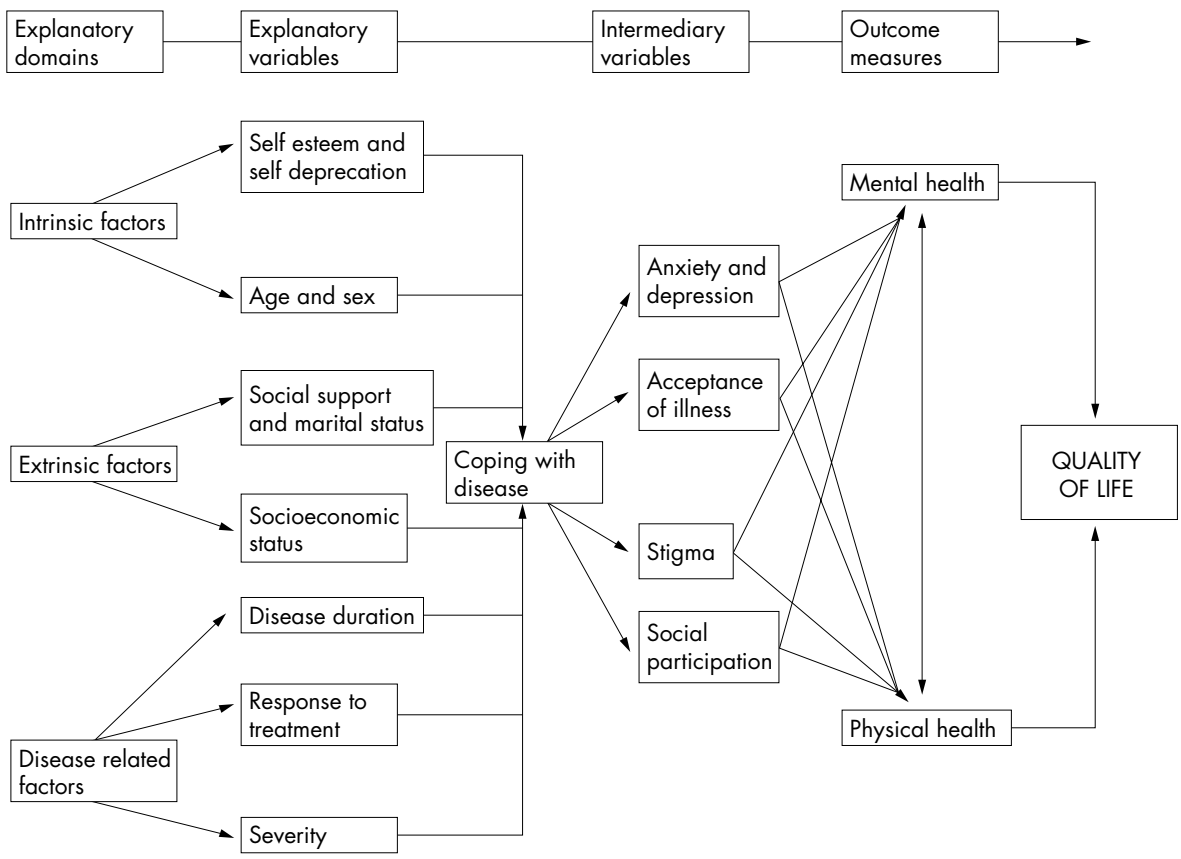

Figure 1 Conceptual scheme of the influence of intrinsic, extrinsic, and disease related factors and coping abilities on the quality of life in cervical dystonia.

scale, which has been used in dystonia, Parkinson's disease, and other neurological conditions. It contains 10 statements, five of which cover self esteem and five self deprecation. Each response is scored from 0 to 4 according to the strength of agreement, producing scores out of 20 for the two domain scores. Low scores indicate low self esteem or a high degree of self deprecation.

Extrinsic factors included aspects of an individual's social environment such as social support, cohabiting, and socioeconomic status. The quantity and quality of support from partners, friends, and family were measured using the multidimensional personal support scale. ${ }^{10}$ Each source of support was assessed in four dimensions. The respondent could rate their level of satisfaction with support received in each dimension on a scale of 0 to 7 . The highest possible score was 84, which indicated complete satisfaction with the support received from all sources. We used a composite educational variable because of the problems of classifying socioeconomic status across different countries and cultures (left school at "minimum" age, stayed on at school for "further" education, obtained "degree" or equivalent professional qualification).

Disease related factors included disease duration, self rated severity (0-10 point scale; a higher score indicates more severe disease) and reported response to botulinum toxin (better, worse, or unchanged).

The above factors were viewed as explanatory variables that could interact in a complex way and determine how an individual copes with a disease.

Coping behaviour was seen as an intermediary domain that mediated the relation between the explanatory variables and the quality of life outcome measure. Coping was assessed in various ways: acceptance of illness, stigma, social participation, anxiety, and depression.

Acceptance of illness was measured using the acceptance of illness scale, ${ }^{11}$ which was developed for use in chronic illnesses such as diabetes and rheumatoid arthritis. The scale contains eight statements (for example, "I have difficulty accepting my illness") with which the respondent is invited to agree or disagree. Each response is scored from 1 to 5 according to the strength of agreement, with the exception of the last question where the marking order is reversed. The total score of 40 was reported, divided by 8 to enable comparison with the other chronic conditions. Higher scores indicated a lower acceptance of illness.

Experience of stigma was measured using the stigma scale, $^{12}$ which was developed for survivors of bowel cancer. There are six general statements that relate to the respondent's self image and relationships with others (for example, "I avoid other people") and these are scored from 0 to 3 according to the strength of agreement. The scores were grouped

Table 1 Description of explanatory, intermediary, and outcome variables by sex

\begin{tabular}{|c|c|c|c|}
\hline Variable & $\begin{array}{l}\text { Men } \\
(n=101)\end{array}$ & $\begin{array}{l}\text { Women } \\
(n=188)\end{array}$ & All $(n=289)$ \\
\hline \multicolumn{4}{|l|}{ Categorical variables } \\
\hline \\
\hline Minimum & $48(47.5)$ & $92(48.9)$ & $140(48.4)$ \\
\hline Further & $25(24.8)$ & $66(35.1)$ & $91(31.5)$ \\
\hline Higher & $28(27.7)$ & 30 (16.0) & $58(20.1)$ \\
\hline \multicolumn{4}{|l|}{ Employment status (\%) } \\
\hline Employed & $38(37.6)$ & $53(28.2)$ & $91(31.5)$ \\
\hline Retired & 45 (44.6) & $81(43.1)$ & $126(43.6)$ \\
\hline Other & $18(17.8)$ & $54(28.7)$ & $72(24.9)$ \\
\hline \multicolumn{4}{|c|}{ Response to botulinum toxin (\%) } \\
\hline Improved & $67(72.8)$ & $119(78.8)$ & $186(76.5)$ \\
\hline \multicolumn{4}{|l|}{ Continuous variables* } \\
\hline Age (years) & $52.8(14.3)$ & $56.7(12.5)$ & $55.3(13.2)$ \\
\hline Disease duration (years) & $11.6(8.2)$ & $12.0(9.3)$ & $11.9(8.9)$ \\
\hline $\begin{array}{l}\text { Global severity ( } 1 \text { =best, } \\
10=\text { worst })\end{array}$ & $5.7(2.2)$ & $5.7(2.2)$ & $5.7(2.2)$ \\
\hline Stigma score & $7.0(3.9)$ & $7.9(4.0)$ & $7.6(4.0)$ \\
\hline Acceptance of illness & $2.76(1.09)$ & $2.60(0.98)$ & $2.66(1.02)$ \\
\hline Social participation & $34.9(10.7)$ & $33.3(10.5)$ & $33.9(10.6)$ \\
\hline Social support & $57.1(17.6)$ & $57.2(19.2)$ & $57.1(18.6)$ \\
\hline Beck anxiety score & $13.1(9.3)$ & $16.1(12.4)$ & $15.0(11.5)$ \\
\hline Beck depression score & $10.4(7.5)$ & $12.8(9.7)$ & $12.0(9.0)$ \\
\hline Self esteem & $14.5(2.6)$ & $14.0(2.8)$ & $14.2(2.7)$ \\
\hline Self deprecation & $10.1(3.3)$ & $11.0(3.4)$ & $10.7(3.4)$ \\
\hline Physical summary score & $52.9(21.4)$ & $46.3(22.0)$ & 48.7 (21.9) \\
\hline Mental summary score & $58.8(20.6)$ & $53.4(22.4)$ & $55.4(21.9)$ \\
\hline
\end{tabular}


Table 2 Age and sex adjusted associations of explanatory and intermediary variables with physical and mental summary scores

\begin{tabular}{|c|c|c|c|c|c|c|}
\hline \multirow[t]{2}{*}{ Variable } & \multicolumn{3}{|c|}{ Physical summary score } & \multicolumn{3}{|c|}{ Mental summary score } \\
\hline & $\beta$ Value & $95 \% \mathrm{Cl}$ & $\mathrm{p}$ Value & $\beta$ Value & $95 \% \mathrm{Cl}$ & $\mathrm{p}$ Value \\
\hline \multicolumn{7}{|l|}{ Intrinsic factors } \\
\hline \multicolumn{7}{|l|}{ Age (years) } \\
\hline $40-49 *$ & -7.5 & -17.0 to 2.0 & & -7.5 & -17.1 to 2.0 & \\
\hline $50-59$ & -7.0 & -16.5 to 2.4 & & -3.4 & -12.9 to 6.1 & \\
\hline $60-69$ & -7.2 & -16.8 to 2.4 & & -5.7 & -15.5 to 4.0 & \\
\hline $70+$ & -13.8 & -24.2 to -3.3 & $0.15 \dagger$ & -4.6 & -15.2 to 5.9 & $0.51 \dagger$ \\
\hline Women & -6.1 & -11.7 to -0.5 & 0.03 & -5.5 & -11.2 to 0.2 & 0.06 \\
\hline Self esteem & 11.7 & 9.4 to 14.1 & $<0.001$ & 13.1 & 10.9 to 15.3 & $<0.001$ \\
\hline Self deprecation & -9.0 & -11.6 to -6.5 & $<0.001$ & -10.9 & -13.3 to -8.4 & $<0.001$ \\
\hline \multicolumn{7}{|l|}{ Extrinsic factors } \\
\hline Single $v$ cohabiting & 2.9 & -3.0 to 8.7 & 0.33 & 2.2 & -3.7 to 8.0 & 0.47 \\
\hline \multicolumn{7}{|l|}{ Educational level } \\
\hline Further & 4.9 & -1.2 to 11.0 & 0.11 & 9.1 & 3.0 to 15.2 & 0.004 \\
\hline Higher & 9.4 & 2.4 to 16.5 & 0.009 & 3.4 & -3.7 to 10.5 & 0.35 \\
\hline \multicolumn{7}{|l|}{ Employment status } \\
\hline Retired & -17.1 & -24.6 to -9.7 & $<0.001$ & -14.4 & -21.8 to -6.9 & $<0.001$ \\
\hline Other & -12.3 & -19.7 to -5.0 & 0.001 & -15.6 & -23.0 to -8.1 & $<0.001$ \\
\hline Social support & 4.8 & 2.1 to 7.6 & 0.001 & 6.1 & 3.4 to 8.9 & $<0.001$ \\
\hline \multicolumn{7}{|c|}{ Disease related factors } \\
\hline \multicolumn{7}{|c|}{ Disease duration (years) } \\
\hline $6-10$ & -1.3 & -8.8 to 6.1 & 0.73 & 3.0 & -4.5 to 10.6 & 0.43 \\
\hline $11-16$ & 4.2 & -3.9 to 12.3 & 0.31 & 3.1 & -5.0 to 11.3 & 0.76 \\
\hline $17+$ & 5.3 & -2.6 to 13.2 & 0.19 & 8.5 & 0.6 to 16.5 & 0.04 \\
\hline \multicolumn{7}{|c|}{ Response to botulinum toxin } \\
\hline No benefit & -8.2 & -15.1 to -1.4 & 0.01 & -7.7 & -14.7 to -0.8 & 0.03 \\
\hline Global severity & -12.2 & -14.6 to -9.9 & $<0.001$ & -11.1 & -13.6 to -8.7 & $<0.001$ \\
\hline \multicolumn{7}{|c|}{ Intermediary variables } \\
\hline Social participation & 7.1 & 4.6 to 9.6 & $<0.001$ & 8.5 & 6.1 to 11.0 & $<0.001$ \\
\hline Stigma & -10.0 & -12.7 to -7.4 & $<0.001$ & -12.0 & -14.5 to -9.5 & $<0.001$ \\
\hline Acceptance of illness & -8.2 & -10.7 to -5.7 & $<0.001$ & -7.4 & -10.0 to -4.9 & $<0.001$ \\
\hline \multicolumn{7}{|l|}{ Anxiety } \\
\hline Mild & -15.9 & -21.3 to -10.6 & $<0.001$ & -18.0 & -23.0 to -12.9 & $<0.001$ \\
\hline Moderate & -22.8 & -29.2 to -16.4 & $<0.001$ & -27.3 & -33.4 to -21.2 & $<0.001$ \\
\hline Severe & -35.1 & -43.0 to -27.3 & $<0.001$ & -38.7 & -46.1 to -31.3 & $<0.001$ \\
\hline \multicolumn{7}{|l|}{ Depression } \\
\hline Mild & -19.9 & -25.9 to -14.0 & $<0.001$ & -19.7 & -25.2 to -14.3 & $<0.001$ \\
\hline Moderate & -29.4 & -36.3 to -22.4 & $<0.001$ & -33.6 & -39.9 to -27.2 & $<0.001$ \\
\hline Severe & -43.3 & -51.0 to -35.7 & $<0.001$ & -48.3 & -55.3 to -41.3 & $<0.001$ \\
\hline
\end{tabular}

using the recommended cut off points, where a score of more than 12 indicates severe stigma.

The level of social participation was measured with the leisure activities scale, ${ }^{13}$ which lists 27 common leisure activities. Respondents score from 0 to 3 on each activity, according to their level of participation. The maximum possible score is 81 , indicating a high level of social participation.

Anxiety was measured with the Beck anxiety index. ${ }^{14}$ The scale contains a list of 21 common symptoms of anxiety that are scored from 0 to 3 according to how frequently the respondent experiences them. The highest possible score is 63, indicating disabling levels of anxiety.

Depression was measured with the Beck depression inventory. ${ }^{15}$ The scale contains 21 questions with four possible responses. The highest possible score is 63. Increasing scores indicate a progressively more severe level of depression, from no depression (0 to 4), through mild depression (5 to 13) and moderate depression (14 to 20), to severe depression (21 and above).

\section{Statistical methods}

Comparison between groups was undertaken either by analysis of variance or by $\chi^{2}$ tests. Multiple least squares linear regression was used to examine predictors of the outcome measures. Assumptions of normality were tested using standard diagnostics and examining the scatterplot of residuals against fitted values. Continuous and discrete explanatory variables were transformed where appropriate and changed into $\mathrm{z}$ scores to enable direct comparison of the $\beta$ coefficients. In some cases, they had to be categorised owing to extreme skewness, which remained even after transformation. Categorical terms were modelled as both dummy and ordinal variables. For continuous explanatory variables, we tested assumptions of linearity by repeating our models with the addition of a quadratic term. All significance tests are two sided at conventional levels of significance $(\mathrm{p}<0.05)$.

\section{RESULTS}

Data were collected on 289 patients (101 men and 188 women), mean age 55 years. The average response rate was $75 \%$ across all centres. The basic descriptive data are presented in table 1. Around one third of the sample was living alone. Women were slightly older, with longer disease duration, lower educational status, and higher scores for both anxiety and depression, but there was little if any sex difference in most of the other variables. Women scored worse for both physical and mental summary scores.

Most of the explanatory and all the intermediary variables showed statistically significant associations with both the physical and the mental summary scores after adjustment for age and sex (table 2 ). Intrinsic personality factors were highly 


\begin{tabular}{|c|c|c|c|c|c|c|}
\hline \multirow[b]{3}{*}{ Variable } & \multicolumn{6}{|c|}{ Physical summary score } \\
\hline & \multicolumn{3}{|c|}{$\begin{array}{l}\text { Adjusted for other intrinsic, extrinsic, and } \\
\text { disease related factors }\end{array}$} & \multicolumn{3}{|c|}{ Adjusted for all variables } \\
\hline & $\beta$ Value & $95 \% \mathrm{Cl}$ & $\mathrm{p}$ Value & $\beta$ Value & $95 \% \mathrm{Cl}$ & $\mathrm{p}$ Value \\
\hline \multicolumn{7}{|l|}{ Intrinsic factors } \\
\hline \multirow{2}{*}{\multicolumn{7}{|c|}{ Age (years) }} \\
\hline $40-49^{*}$ & -3.3 & -11.4 to 4.9 & & & & \\
\hline $50-59$ & 5.0 & 13.3 to 3.3 & & -4.6 & -12.8 to 3.5 & \\
\hline $60-69$ & 0.1 & -9.1 to 9.3 & & -0.3 & -9.4 to 8.7 & \\
\hline $70+$ & -6.1 & -16.1 to 3.8 & $0.39 \dagger$ & -7.7 & -17.5 to 2.2 & $0.25 \dagger$ \\
\hline Women & -2.6 & -7.7 to 2.5 & 0.32 & -3.2 & -8.1 to 1.8 & 0.21 \\
\hline Self esteem & 3.7 & 0.5 to 6.8 & 0.02 & 1.2 & -1.9 to 4.4 & 0.44 \\
\hline Self deprecation & -5.2 & -8.0 to -2.5 & $<0.001$ & -1.1 & -4.0 to 1.9 & 0.48 \\
\hline \multicolumn{7}{|l|}{ Extrinsic factors } \\
\hline $\begin{array}{l}\text { Single } v \text { cohabiting } \\
\text { Educational level }\end{array}$ & -2.6 & -7.7 to 2.6 & 0.32 & -3.3 & -8.4 to 1.9 & 0.22 \\
\hline Further & -1.7 & -7.2 to 3.7 & 0.53 & -3.9 & -9.3 to 1.5 & 0.16 \\
\hline Higher & 3.2 & -2.7 to 9.2 & 0.28 & 4.8 & -1.1 to 10.7 & 0.11 \\
\hline \multicolumn{7}{|l|}{ Employment status } \\
\hline Retired & -7.7 & -14.3 to -1.2 & 0.02 & -5.6 & -12.0 to 0.9 & 0.09 \\
\hline Other & -3.3 & -10.0 to 3.5 & 0.34 & -1.5 & -7.9 to 4.9 & 0.64 \\
\hline Social support & 2.0 & -0.6 to 4.6 & 0.13 & 1.4 & -1.2 to 4.0 & 0.30 \\
\hline \multirow{2}{*}{\multicolumn{7}{|c|}{ Disease related factors }} \\
\hline & \multicolumn{6}{|c|}{ Disease duration (years) } \\
\hline $6-10$ & 2.5 & -3.7 to 8.7 & 0.43 & 2.5 & -3.3 to 8.4 & 0.39 \\
\hline $11-16$ & 8.0 & 1.1 to 14.9 & 0.02 & 7.0 & 0.2 to 13.7 & 0.04 \\
\hline $17+$ & 11.1 & 4.3 to 17.9 & 0.002 & 8.5 & 1.8 to 15.3 & 0.01 \\
\hline \multicolumn{7}{|c|}{ Response to botulinum toxin } \\
\hline No benefit & 0.5 & -5.6 to 6.7 & 0.86 & 1.9 & -4.2 to 7.9 & 0.55 \\
\hline Global severity & -8.7 & -11.4 to -5.9 & $<0.001$ & -6.1 & -8.9 to -3.3 & $<0.001$ \\
\hline \multicolumn{7}{|l|}{ Intermediary variables } \\
\hline Social participation & & & & -0.0 & -2.6 to 2.5 & 0.99 \\
\hline Stigma & & & & -1.5 & -4.6 to 1.6 & 0.34 \\
\hline Acceptance of illness & & & & -2.0 & -4.5 to 0.5 & 0.12 \\
\hline \multicolumn{7}{|l|}{ Anxiety } \\
\hline Mild & & & & -7.4 & -13.1 to -1.8 & 0.01 \\
\hline Moderate & & & & -6.8 & -14.0 to 0.4 & 0.07 \\
\hline Severe & & & & -12.2 & -22.4 to -2.0 & 0.02 \\
\hline \multicolumn{7}{|l|}{ Depression } \\
\hline Mild & & & & -10.4 & -17.7 to -3.2 & 0.005 \\
\hline Moderate & & & & -13.9 & -23.5 to -4.3 & 0.005 \\
\hline Severe & & & & -19.1 & -31.7 to -6.6 & 0.003 \\
\hline
\end{tabular}

predictive. These personality factors were more strongly associated with mental health, but the differences were not large. Women scored worse than men on both outcomes. The oldest age group scored worse on the physical summary score, but otherwise there was no real age effect. All the extrinsic factors were predictive except for cohabiting status, although higher levels of social support were associated with better physical and mental summary scores. Subjects with a higher educational level also seemed to have better scores, although this trend was not consistent. Patients who reported no benefit from botulinum toxin had worse global severity and were found to have lower physical and mental summary scores. A longer duration of disease severity was associated with better scores.

Intermediary variables tended to show stronger associations. Not surprisingly both anxiety and depression were highly predictive of worse mental scores but perhaps less obvious was the fact that this association was almost as strong with the physical summary score. As predicted, less social participation, more stigma, and less acceptance of illness were all highly predictive of worse mental and physical scores.

In multivariable analyses, many of the explanatory variables for the physical summary score were markedly attenuated (table 3). Sex, educational level, social support, and response to botulinum toxin were all no longer statistically significant. Self esteem, self deprecation, retired status, and patient severity score remained significant predictors but with weaker effect estimates. The beneficial effect of disease duration was increased after multivariable adjustment, with a clear trend effect $(p<0.001)$. Further adjustment for the intermediary variables weakened the effects of most of the explanatory variables, although disease duration and patient severity remained significant predictors. The largest effect sizes were for the severity of anxiety and depression, the latter having a greater negative effect on physical score.

Similar findings were seen with the mental summary score (table 4). Again, disease duration and severity score were the best predictors, but self deprecation and poor social support were also predictors of worse mental scores. After adjustment for intermediary variables, cohabiting status, self deprecation, disease duration, and patient severity score continued to have a significant association, but anxiety and depression scores showed larger effects.

\section{DISCUSSION}

This is the first study to examine a comprehensive range of factors that could explain quality of life in patients with cervical 


\begin{tabular}{|c|c|c|c|c|c|c|}
\hline \multirow[b]{3}{*}{ Variable } & \multicolumn{6}{|c|}{ Mental summary score } \\
\hline & \multicolumn{3}{|c|}{$\begin{array}{l}\text { Adjusted for other intrinsic, extrinsic, } \\
\text { and disease related factors }\end{array}$} & \multicolumn{3}{|c|}{ Adjusted for all variables } \\
\hline & $\beta$ Value & $95 \% \mathrm{Cl}$ & $\mathrm{p}$ Value & $\beta$ Value & $95 \% \mathrm{Cl}$ & $\mathrm{p}$ Value \\
\hline \multicolumn{7}{|l|}{ Intrinsic factors } \\
\hline \multicolumn{7}{|l|}{ Age (years) } \\
\hline $40-49 *$ & -5.0 & -12.8 to 2.7 & & -5.3 & -12.7 to 2.1 & \\
\hline $50-59$ & -2.9 & -10.9 to 5.0 & & -3.9 & -11.3 to 3.5 & \\
\hline $60-69$ & -0.3 & -9.1 to 8.5 & & -2.9 & -11.2 to 5.4 & \\
\hline $70+$ & 1.6 & -8.0 to 11.2 & $0.49 \dagger$ & -1.4 & -10.5 to 7.6 & $0.66 \dagger$ \\
\hline Women & -1.8 & -6.6 to 3.1 & 0.48 & -1.9 & -6.4 to 2.7 & 0.42 \\
\hline Self esteem & 4.6 & -6.6 to 3.1 & 0.48 & 1.5 & -1.4 to 4.4 & 0.30 \\
\hline Self deprecation & -6.7 & -9.3 to -4.1 & 0.003 & -2.8 & -5.5 to -0.1 & 0.04 \\
\hline \multicolumn{7}{|l|}{ Extrinsic factors } \\
\hline Single $v$ cohabiting & -4.2 & -9.2 to 0.7 & 0.09 & -5.0 & -9.8 to -0.3 & 0.04 \\
\hline \multicolumn{7}{|l|}{ Educational level } \\
\hline Further & 1.0 & -4.2 to 6.2 & 0.71 & -0.4 & -5.3 to 4.6 & 0.89 \\
\hline Degree & -2.2 & -7.9 to 3.5 & 0.44 & -0.7 & -6.1 to 4.7 & 0.79 \\
\hline \multicolumn{7}{|l|}{ Employment status } \\
\hline Retired & -4.4 & -10.7 to 1.8 & 0.17 & -2.5 & -8.5 to 3.3 & 0.39 \\
\hline Other & -4.0 & -10.5 to 2.4 & 0.22 & -2.6 & -8.5 to 3.2 & 0.38 \\
\hline Social support & 2.8 & 0.3 to 5.3 & 0.03 & 2.1 & -0.3 to 4.5 & 0.08 \\
\hline \multirow{2}{*}{\multicolumn{7}{|c|}{$\begin{array}{l}\text { Disease related factors } \\
\text { Disease duration (years) }\end{array}$}} \\
\hline & \multicolumn{6}{|c|}{ Disease duration (years) } \\
\hline $6-10$ & 6.8 & 0.8 to 12.7 & 0.03 & 6.8 & 1.5 to 12.2 & 0.01 \\
\hline $11-16$ & 6.6 & 0.1 to 13.2 & 0.05 & 5.4 & -0.7 to 11.6 & 0.08 \\
\hline $17+$ & 13.5 & 7.0 to 20.1 & $<0.001$ & 11.0 & 4.8 to 17.1 & 0.001 \\
\hline \multicolumn{7}{|c|}{ Response to botulinum toxin } \\
\hline No benefit & -0.9 & -6.8 to 5.0 & 0.77 & -0.5 & -6.1 to 5.0 & 0.85 \\
\hline Global severity & -7.4 & -10.1 to -4.8 & $<0.001$ & -5.1 & -7.7 to -2.6 & $<0.001$ \\
\hline \multicolumn{7}{|l|}{ Intermediary variables } \\
\hline Social participation & & & & -0.4 & -2.7 to 1.9 & 0.72 \\
\hline Stigma & & & & -1.4 & -4.3 to 1.4 & 0.32 \\
\hline Acceptance of illness & & & & 0.1 & -2.2 to 2.5 & 0.91 \\
\hline \multicolumn{7}{|l|}{ Anxiety } \\
\hline Mild & & & & -9.9 & -15.1 to -4.8 & $<0.001$ \\
\hline Moderate & & & & -13.2 & -19.8 to -6.5 & $<0.001$ \\
\hline Severe & & & & -18.7 & -28.0 to -9.4 & $<0.001$ \\
\hline \multicolumn{7}{|l|}{ Depression } \\
\hline Mild & & & & -9.6 & -16.2 to -3.0 & 0.005 \\
\hline Moderate & & & & -15.6 & -24.4 to -6.8 & 0.001 \\
\hline Severe & & & & -16.1 & -27.6 to -4.6 & 0.006 \\
\hline
\end{tabular}

dystonia. While patients reported worse quality of life for the physical summary score, the mental health score was also strikingly reduced compared with the general population. ${ }^{16}$ This marked effect on mental wellbeing may reflect the obvious stigmatising effect of living with such a visible disorder. Not surprisingly, the severity of the condition and whether the patient showed a response to botulinum toxin both predicted quality of life. However, intrinsic personality features (self esteem, self deprecation) and educational status also modified the patients' ability to cope with the disease. Longer disease duration was associated with better quality of life, which is probably related to the development of successful coping strategies. We had an a priori hypothesis that an individual's ability to get on with their life, despite their disease, would influence their social participation, perceptions of stigma, and acceptance of illness, as well as feelings of anxiety and depression. These intermediary variables were all highly significant predictors of quality of life and were stronger than the intrinsic, extrinsic, and disease related factors. In our final models, most of the significant variables were no longer predictive. This suggests that their initial predictive effect was mediated mainly through psychological processes such as depression and anxiety, though disease duration and severity remained predictors.

\section{Study limitations}

It is important to consider the limitations of our study. First, all patients were recruited from specialist centres. This enhances the validity of the diagnosis but reduces the generalisability of our findings as our patients are unlikely to be typical of patients with cervical dystonia in general. Second, while our response rate was moderately high, it is possible that patients with severe depression were more likely to fail to complete the questionnaire. Exclusion of such patients will not bias our findings unless the associations between exposure and outcome variables differed in this subgroup compared with the rest of the study sample. Third, many of the variables we tried to test in our model will be measured imprecisely using relatively crude questionnaire data. It is therefore important to appreciate that independent effects seen in multivariable models may be misleading if the degree of imprecision varies across exposures. ${ }^{17}{ }^{18}$

\section{Quality of life in comparable conditions}

The factors that influence quality of life have been studied in other, comparable conditions.

In multiple sclerosis, perceptions of social support and self efficacy were important predictors of adaptation to the 
illness. ${ }^{19-21}$ Self efficacy (defined as the ability to control negative thoughts) was a far stronger predictor of mood and social activity than the clinical variables.

Studies of stroke are generally consistent with our observations. One study found that subjective wellbeing after stroke (defined as "satisfaction," "strength," "calmness," and "cheerfulness") was related to female sex, older age, good general and mental health, and a strong social network. ${ }^{22}$ Similarly two studies measuring handicap and quality of life after a stroke found that these outcomes were related to perception of control and social support ${ }^{23}$ as well as depression. ${ }^{24}$

In rheumatoid arthritis, anxiety and depression were found to be stronger predictors of pain than clinical variables. ${ }^{25}{ }^{26}$ The ability to continue working after the onset of the disease was significantly related to lower reports of pain and depression, irrespective of disease severity. ${ }^{27}$ Low self efficacy and a perception of helplessness were also predictors of disability, ${ }^{28}{ }^{29}$ as was a low level of formal education. ${ }^{30}$ While disability was the main predictor of depression among rheumatoid arthritis patients, sex, disease duration, social isolation, and economic deprivation were also important factors.

Recent studies of Parkinson's disease emphasise the effect of depression of quality of life. ${ }^{31-33}$ However, its effects can be mitigated by having a sense of "mastery" (measured by "locus of control" and "self efficacy") over the condition ${ }^{34}$ and using active coping strategies. "Mastery" was also an important mediator between disease severity and quality of life in epilepsy. ${ }^{36}$

As in dystonia, fatigue and depression had an inverse relation with quality of life in epilepsy. ${ }^{37}$ Seizure frequency appeared to be the main determinant, however, and patients whose condition was controlled by surgery or drug treatment reported quality of life scores similar to the general population. ${ }^{38-40}$

\section{Conclusions}

Our results are similar to those found in other diseases where psychosocial variables are important in either mediating or modifying the effects of disease severity on the quality of life. The ability to reduce disease severity through pharmacological or other interventions will have a major benefit on both physical and mental wellbeing in patients with cervical dystonia. However, there is a clear need to recognise and treat patients with anxiety and depression. Given the marked role of other psychological factors-such as self deprecation and acceptance of the illness - cognitive or other types of psychological therapy should be considered as well as conventional drug treatment, as on the basis of our results the former may have more lasting beneficial effects. Increased social support either through family or patient support groups may have some additional benefit for mental wellbeing.

\section{ACKNOWLEDGEMENTS}

We thank the European Dystonia Federation for funding the study, Alistair Newton for helping organise it, and all the participants for taking part. Bristol is the lead centre for the MRC Health Services Research Collaboration.

\section{ESDE participants}

London (UK): L Camfield, Dr T T Warner, Dr M Jahanshahi; Innsbruck (Austria): Dr J Wissel, Prof W Poewe; Turku (Finland): Dr R J Marttila; Bordeaux (France): Prof P Burbaud, Prof A Lagueny; Rome 1 (Italy): Dr Antonio Curra, Prof A Beradelli; Rome 2 (Italy): Dr Enza-Maria Valente, Prof A Albanese; Munich (Germany): Dr F Asmus, Dr T Gasser; Barcelona (Spain): Dr F Marti, Prof E Tolosa.

\section{Authors' affiliations}

Y Ben-Shlomo, Department of Social Medicine, MRC Health Services Collaboration, University of Bristol, Bristol, UK

L Camfield, T T Warner, University Department of Clinical
Neurosciences, Royal Free and University College Medical School, Royal Free Campus, London NW3, UK

\section{REFERENCES}

1 Epidemiological Study of Dystonia in Europe Collaborative Group. Sex-related influences on the frequency and age of onset of primary dystonia. Neurology 1999;53:1871-3.

2 Epidemiological Study of Dystonia in Europe Collaborative Group A prevalence study of primary dystonia in eight European countries. J Neurol 2000;24:787-93.

3 Nutt JG. Aronson A, Kurland LT, et al. Epidemiology of focal and generalized dystonia in Rochester, Minnesota. Mov Disord 1988;3:188-94

4 Jahanshahi M. Psychosocial factors and depression in torticollis. J Psychosom Res 1991;35:497-507.

5 Nickel T, Heinen F, Scheidt CE, et al. Spasmodic torticollis - a multicenter study on behavioural aspects. III. Psychosocial changes and coping. Behav Neurol 1996;9:25-34

6 Chan J, Brin MF, Fahn S. Idiopathic cervical dystonia: clinical characteristics. Mov Disord 1991;6:119-26.

7 Camfield L. Quality of life in cervical dystonia. Mov Disord 2000;15(suppl).

8 Ware JE, Sherbourne CD. The MOS 36-item short-form health survey (SF-36). I. Conceptual framework and item selection. Med Care 1992; 30:473-83.

9 Rosenberg M. Society and the adolescent self image. Princeton, NJ: Princeton University Press, 1965

10 Zimet GD, Powell SS, Farley GK, et al. Psychometric characteristics of the MSPSS. J Pers Assess 1990;55:610-17.

11 Felton BJ, Revenson TA. Coping with chronic illness: a study of illness controllability and the influence of coping strategies on psychological adjustment. J Consult Clin Psychol 1984;2:343-53.

12 Macdonald LD, Anderson HR. Stigma in people with rectal cancer: a community study. J Epidemiol Community Health 1984;38:284-90.

13 Kelly JR, Steinkamp MW, Kelly JR. Later life satisfaction: does leisure contribute? Leisure Sci 1987:9:189-200.

14 Beck AT, Epstein N, Brown G, et al. An inventory for measuring clinical anxiety: psychometric properties. J Consult Clin Psychol 1986;56:893-97.

15 Beck AT, Ward $\mathrm{CH}$, Mendelson $\mathrm{M}$, et al. An inventory for measuring depression. Arch Gen Psychiatry 1961;4:561-71.

16 Jenkinson C, Coulter A, Wright L. Short form 36 (SF36) health survey questionnaire: normative data for adults of working age. BM 1993:306: 1437-40.

17 Phillips A, Davey Smith G. How independent are "independent" effects? Relative risk estimation when correlated exposures are measured imprecisely. J Clin Epidemiol 1990;44:1223-31.

18 Davey Smith G, Phillips AN. Confounding in epidemiological studies: why "independent" effects may not be all they seem. BM 1992;305:757-9

19 Barnwell AM, Kavanagh DJ. Prediction of psychological adjustment to multiple sclerosis. Soc Sci Med 1997;45:411-18.

20 Wassem R. Self-efficacy as a predictor of adjustment to multiple sclerosis. J Neurosci Nurs 1992;24:224-9.

21 Wineman NM. Adaptation to multiple sclerosis: the role of social support, functional disability, and perceived uncertainty. Nurs Res 1990;39:294.

22 Bruun Wyller T, Holmen J, Laake $\mathrm{P}$, et al. Correlates of subjective well-being in stroke patients. Stroke 1998;29:363-7.

23 Gottlieb A, Golabnder H, Bar-Tal Y, et al. The influence of social support and perceived control on handicap and quality of life after stroke. Aging 2001;13:11-15

24 Carod-Artal J, Egido JA, Gonzalez JL, et al. Quality of life among stroke survivor evaluated 1 year after stroke: experience of a stroke unit. Stroke 2000;31:2995-3000.

25 Newman SP, Fitzpatrick R, Lamb R, et al. The origins of depressed mood in rheumatoid arthritis. J Rheumatol 1989;16:740-4.

26 Hawley DJ, Wolfe F. Anxiety and depression in patients with rheumatoid arthritis. Arthritis Rheum 1988;15:932-941.

27 Fifield J, Reisine ST, Grady K. Work disability and the experience of pain and depression in rheumatoid arthritis. Soc Sci Med 1991;35:579-85

28 Lorig K, Chastain RL, Ung E, Shoor S, Holman HR. Development and evaluation of a scale to measure perceived self-efficacy in people with arthritis. Arthritis Rheum 1989;32:91-5

29 Nicassio PM, Wallston KA, Callhan LF, et al. The measurement of helplessness in rheumatoid arthritis: the development of the arthritis helplessness index. J Rheumatol 1985;12:462-7.

30 Callahan LR, Smith WJ, Pincus T. Self-report questionnaires in five rheumatic diseases: comparison of health status constructs and associations with formal education level. Arthritis Care Res 1989;4:122-31.

31 Kuopio AM, Marttila R, Helenius $\mathrm{H}$, et al. The quality of life in Parkinson's disease. Mov Disord 2000;15:216-23.

32 Slaughter JR, Slaughter KA, Nichols D, et al. Prevalence, clinical manifestations, aetiology, and treatment of depression in Parkinson's disease. J Neuropsychiatry Clin Neurosci 2001;13:187-96.

33 Allain H, Shuck S, Mauduit N. Depression in Parkinson's disease. BM 2000;320: 1287-8

34 Koplas PA, Gans HB, Wisely MP, et al. Quality of life and Parkinson's disease. J Gerontol Ser A: Biol Sci Med Sci 1999;54:M197-202. 
35 Schreurs KMG, DeRidder DTD, Bensing JM. A one year study of coping, social support, and quality of life in Parkinson's disease. Psychol Health 2000; 15:109-21.

36 Amir M, Roziner I, Knoll A, et al. Self efficacy and social support as mediators in the relation between disease severity and quality of life in patients with epilepsy. Epilepsia 1999:40:216-24.

37 Ettinger $\mathbf{A B}$, Weisbrot DM, Krupp LB, et al. Fatigue and depression in epilepsy. J Epilepsy 1998;11:105-9.
38 Malmgren K, Sullivan M, Ekstedt $G$, et al. Health-related quality of life after epilepsy surgery: a Swedish multicenter study. Epilepsia $7 ; 38: 830-8$

39 Stavem K, Loge JH, Kaasa S. Health status of people with epilepsy compared with a general reference population. Epilepsia 2000;41:85-90.

40 Leidy NK, Elixhauser A, Vickrey B, et al. Seizure frequency and the health related quality of life of adults with epilepsy. Neurology 1999;53:162-6.

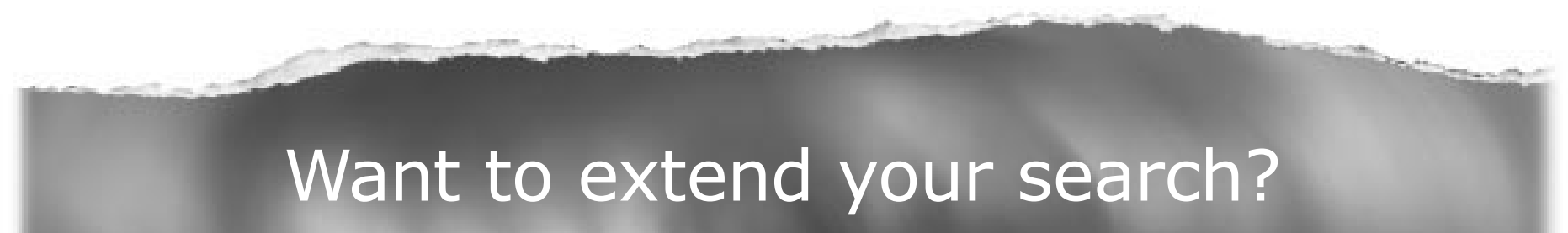

\section{Cross journal searching}

If you can't find what you are looking for in the Journal of Neurology, Neurosurgery, and Psychiatry you can extend your search across many of the more than 200 journals available for selection. You can restrict your search to specific subject areas (eg, clinical medicine, basic research), or select specific journals, or search all available titles.

\section{www.jnnp.com}

